\title{
CONVENTIONAL TREATMENT OF SURFACE WATER USING MORINGA OLEIFERA SEEDS EXTRACT AS A PRIMARY COAGULANT
}

\author{
SULEYMAN A. MUYIBI ${ }^{+*}$, AHMED HISSEIN M BIRIMA ${ }^{*}$, THAMER A. MOHAMMED ${ }^{\ddagger}$, \\ MEGAT JOHARI M. M. NOOR \\ ${ }^{+}$Department of Biotechnology Engineering, Faculty of Engineering, International Islamic \\ University Malaysia, 53100 Kuala Lumpur, Malaysia. \\ * Department of Civil Engineering, Faculty of Engineering Universiti Putra Malaysia, 43400 \\ Serdang, Selangor, Malaysia. \\ *e-mail: suleyman@iiu.edu.my
}

\begin{abstract}
The present study involved the use of a model pilot scale water treatment plant to treat turbid surface water from a stream using processed Moringa oleifera seed with $25 \% \mathrm{w} / \mathrm{w}$ oil extracted as primary coagulant. The water treatment plant was made up of four unit operations: coagulation, flocculation, sedimentation, and filtration (rapid sand filter). Test runs were carried out for three hours per run over a three-month period with turbidities ranging from 18 to 261 NTU. The turbidity, $\mathrm{pH}$, and alkalinity as well as the filter head loss were measured every 30 minutes during the experimental runs. Average turbidity removal of up to $96 \%$ at an effective doses of 20 and $30 \mathrm{mg} / \mathrm{l}$ of oil extracted M. oleifera for low $(<50 \mathrm{NTU})$ and moderate turbidity $(<100 \mathrm{NTU})$ water respectively was observed doses $50-80 \mathrm{mg} / \mathrm{l}$ for high turbidity (> $100 \mathrm{NTU}$ ) water. $M$. oleifera seed extract was found to have no significant effect on $\mathrm{pH}$ or alkalinity of the water. The residual turbidities measured during most of the test runs satisfied the Malaysian Guideline for Drinking Water Supplies.
\end{abstract}

Key Words: Moringa oleifera, primary coagulant, coagulation, pilot plant, filtration.

\section{INTRODUCTION}

Many coagulants are widely used in conventional water-treatment process for turbidity removal during potable water production. These coagulants may be classified as inorganic, synthetic organic polymer, and natural polymer. These coagulants are used for various purposes depending on the chemical characteristics of the water to be treated. Aluminium salts are by far the most widely used coagulant in water and wastewater treatment. However, recent studies have pointed out several serious drawbacks in using alum salts [13] such as Alzheimer's disease and similar health related problems associated with residual alum in treated waters, beside production of large sludge volumes. There is also the problem of reaction of alum with natural alkalinity present in water leading to reduction of $\mathrm{pH}$ and a low efficiency in coagulation of cold waters [2]. Ongoing studies to produce more effective aluminium coagulants, such as polyaluminum chloride (PAC), 
have not corrected all the drawbacks mentioned above [2]. Ferric salts and synthetic polymers have also been used as coagulants but with limited success because of similar disadvantages manifested in the use of aluminium salts.

In addition to these problems, chemicals used for water treatment in developing countries constitute a high percentage of annual running expenditure of water treatment companies. The costs of these chemicals have also been increasing at an alarming rate because local manufacturing companies cannot cope with the demand for these chemicals in other industrial applications. Therefore, the shortfall has to be imported with scarce convertible foreign currency. These problems force many water treatment companies to resort to under-dosing of chemicals so as to meet the increasing water demand. The result is the supply of poor quality water, especially during the rainy season, when suspended solids concentration and other pollutants in surface water are very high $[3,4]$.

On the other hand, naturally occurring coagulants are usually presumed safe for human health. Some studies on natural coagulants have been carried out and various natural coagulants have been produced or extracted from microorganisms, animals, or plants [5].

Moringa oleifera (family Moringaceae) is a tropical plant known to contain coagulating/flocculating compounds in the seeds. Many researchers have used M. oleifera seed as a primary coagulant, for water treatment [1-4, 6, 7]. Many studies [1, 2, 6, 8, 9-12] have been carried out on the performance of $M$. oleifera seeds as a primary coagulant, coagulant aid and as conjunctive with alum. M. oleifera showed a high coagulation activity for the high turbidity water. The coagulation activity was low for low turbidity water. Results of only three pilot scale studies [9 - 11] using M. oleifera seeds extract as a primary coagulant in turbid surface water treatment worldwide have been documented.

The main objective of the present study was to investigate the use of a model pilot scale water treatment plant to evaluate the efficiency of $M$. oleifera seeds with $25 \%$ w/w seed oil extracted in the treatment of turbid surface water from a stream. In previous studies by others [9-11], M. oleifera seed used was not processed to remove some of the oil content. It has, however, been found that processing of the seed to remove the oil improved the coagulation efficiency of the seeds $[12,13]$. Based on results from a related study, in which selected oil removals were observed to give enhanced coagulation properties to the M. oleifera seed extract with the best results achieved from $25 \% \mathrm{w} / \mathrm{w}$ oil extracted [13], $25 \% \mathrm{w} / \mathrm{w}$ oil was extracted from $M$. oleifera seed kernel.

\section{EXPERIMENTAL}

\subsection{Materials and Methods}

\subsubsection{Pilot Plant Design and Fabrication}

A pilot water treatment plant was designed and built to a distorted scale of $1 / 40$ horizontal and 1/15 vertical. The model treatment plant schematic is shown in Figure 1. It was located near a small stream at the hydraulic laboratory in the Department of Civil Engineering Faculty of Engineering at Universiti Putra Malaysia in Serdang, Selangor 
State of Malaysia. Raw water was pumped into the overhead tank of the pilot plant. The plant was designed and constructed as a compact system that could be moved easily.

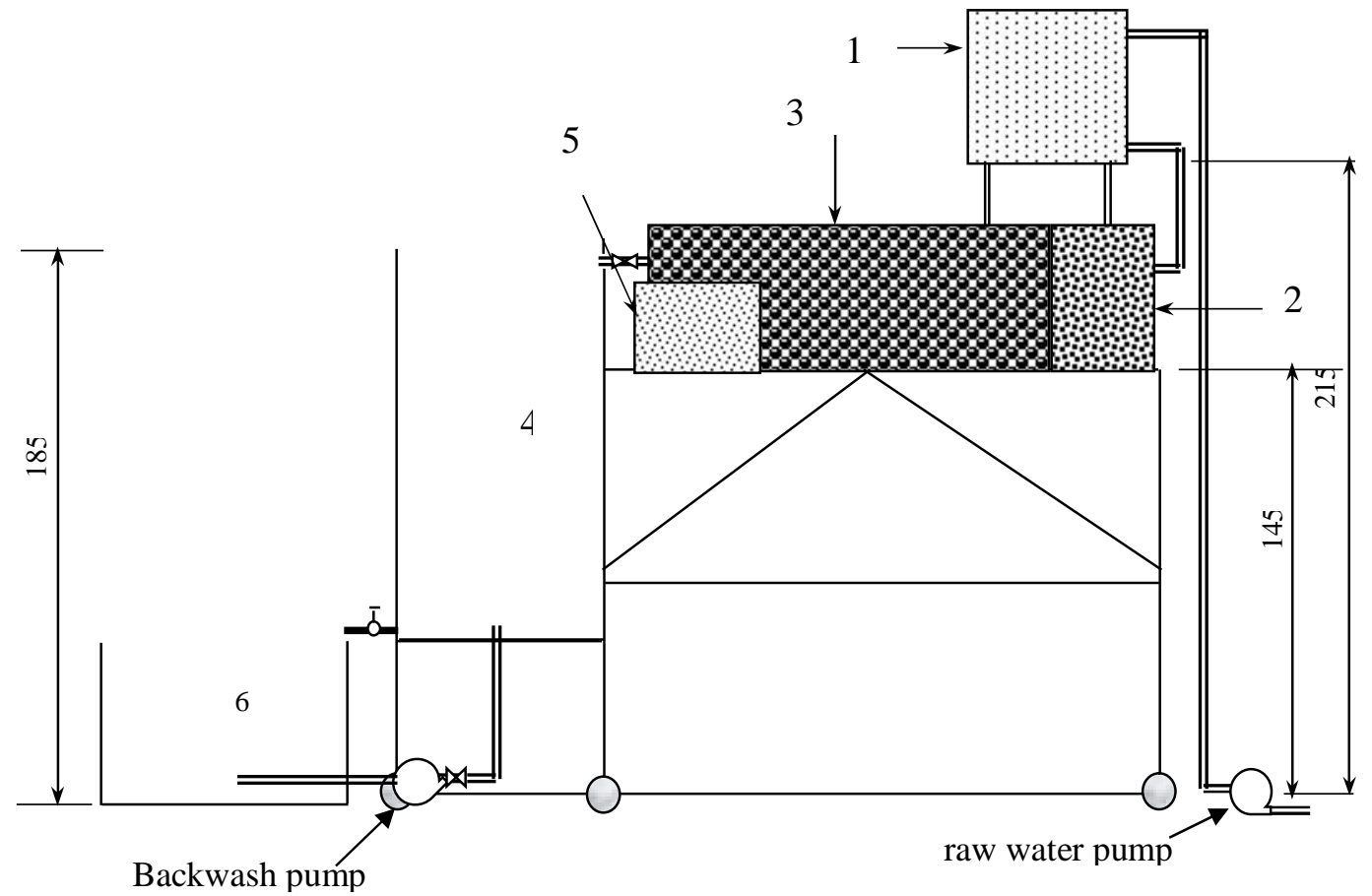

1. Raw water tank with automatic flow rate controller and flow meter

2. Coagulation tank

3. Flocculation / settling tank with inclined plates

4. Rapid gravity filter with underdrain and manometer

5. Coagulant dosing tanks with dosing pumps

6. Treated water tank with backwash pump

Fig. 1: Schematic of Pilot Scale Water Treatment Plant.

\subsubsection{Pilot Plant Details.}

Figure 1 shows the schematic diagram of the pilot plant. The pilot plant consisted of a raw water inlet pipe connected to a small centrifugal pump, raw water tank (1) equipped with an automatic flow level controller and flow meter. It has a coagulant dosing tank (5) equipped with variable speed Masterflex pump (Cole-Palmer Instruments, USA) which was connected to the coagulation and flocculation units $(2,3)$ equipped with IKA $R W$ variable speed digital mixers (IKA Works, Malaysia). A settling unit equipped with inclined plates (3) and connected to rapid gravity sand filter equipped with a manometer (4), and treated water tank (6).

\subsection{Water Sample}

The raw water used in this study was pumped from the stream located near the Hydraulics laboratory. The raw water quality parameters measured during the 
experimental runs were; $\mathrm{pH} 7.1$ to 7.5 ; Alkalinity 0.78 to $2.8 \mathrm{mg} / \mathrm{l}$ as $\mathrm{CaCO}_{3}$; and turbidity 18 to 261 NTU.

\subsection{Preparation of M. oleifera Seed Suspension}

Dry M. oleifera seeds used in the study were obtained from trees around Sri Serdang area of Selangor state, Malaysia. The seed wings and coat were removed and the seed kernel dried in the oven at $50{ }^{\circ} \mathrm{C}$ for 24 hours. The seeds were ground using a domestic food blender. Oil was extracted from the ground seed using a Soxhlet apparatus and hexane as the solvent. Only $25 \% \mathrm{w} / \mathrm{w}$ oil was extracted from the seed kernel because in a previous related study, it was observed that extraction of $25 \% \mathrm{w} / \mathrm{w}$ oil from $M$. oleifera seed powder gave the best performance when applied to coagulation of turbid water [13]. Five grams of oil extracted seeds (remaining cake) powder was blended at high speed for two minutes in a variable speed domestic food processor (National MJ- C85N) with 200 $\mathrm{ml}$ of distilled water added. The resulting suspension was filtered through a clean muslin cloth in a beaker and the filtrate made up to a final volume of $500 \mathrm{ml}$ to yield a stock solution of approximately $10000 \mathrm{mg} / \mathrm{l}$.

\subsection{Equipment}

A Jar test apparatus (Jar Tester CZ 150) was used to obtain the optimum M. oleifera coagulant dose for each experimental run. A portable Turbidimeter (Hach model 2100P) was used to measure the turbidity. Filter head loss development was measured using a manometer (Armfield Instruments, UK) with plastic small bore tubing mounted on a wooden board connected to different levels in the rapid gravity filter.

\subsection{Experimental methods}

The experimental program followed in this study consisted of two parts. Firstly, a sample of raw water was collected from the overhead tank and jar tests carried out to determine the effective dose for each experimental run. The stock solution of M. oleifera required for the 3-hour experimental run was prepared according to the effective dose obtained from the jar tests. The flow rate was set and the dosing pump calibrated to the required flow rate. During each run water samples were taken every 30 minutes from the overhead tank (initial sample), settling tank and from the treated water. Turbidity, $\mathrm{pH}$, and alkalinity were measured for both raw water and treated water from the filter outlet according to standard guidelines and procedures [14]. The filter head losses at different levels in the manometer tubing were also measured and recorded every 30 minutes.

\section{RESULTS AND DISCUSSION}

\subsection{Turbidity removal}

\subsubsection{Low turbidity $(<50$ NTU)}

Figure 2 shows the average results of 3 runs of 9 hours duration when the surface water turbidity was low varying from $18.0-28.0$ NTU. The residual turbidity varied from 4.5 to 
5.2 NTU which was well within the Malaysian Minimum Guideline for Drinking Water Supplies. It is pertinent to note that $M$. oleifera performed very well as a primary coagulant in the removal of turbidity from water with low initial turbidity in contrast to the results obtained from previous studies $[4,2,9,10]$ which all concluded that since the bioactive constituents in $M$. oleifera seed extract is a low molecular weight short chain polyelectrolyte, it would be inefficient in the removal of turbidity from water with low initial turbidity. A possible reason which may be postulated for this observation is the method of preparation of $M$. oleifera used which involved extraction of oil of up to $25 \%$ of kernel weight ( $83 \%$ oil removal) from the powdered seed kernel before using the residual cake as primary coagulant. All previous studies in which $M$. oleifera seed extract was used as primary coagulant, no oil was extracted from the seed kernel before application.

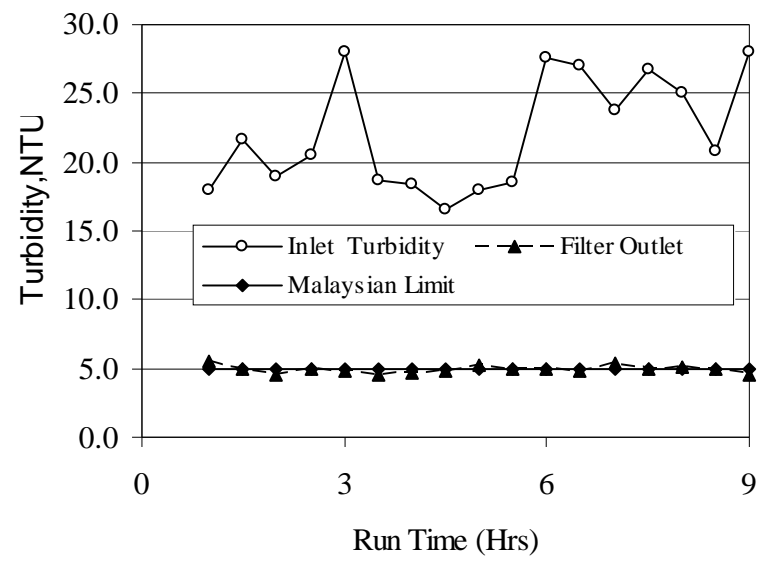

Fig. 2: Turbidity of inlet and filtered outlet at a dose of $30 \mathrm{mg} / \mathrm{L}$ using $25 \% \mathrm{w} / \mathrm{w}$ oil extracted M. oleifera seed (Initial Turbidity of water 18 to 28 NTU)

\subsubsection{Moderate turbidity $(50<$ turbidity $<100$ NTU)}

Figure 3 presents the average results for moderate turbidity that varied from 65 to 90 NTU. The effective dosage of $M$. oleifera used was $30 \mathrm{mg} / \mathrm{l}$. The turbidity dropped from 77.8 NTU to 5.6 NTU after filtration at the beginning of the experiment and reduced gradually to 4.5 NTU, satisfying the Malaysian Guideline for Drinking Water Supplies. The overall turbidity removal after filtration varied from $91.9 \%-94.9 \%$. The gradual improvement in turbidity removal within the experiment run may have been due to the improvement in flow conditions in the filter bed because the filter was operated for 12 hours without backwashing during the initial commissioning before the experimental runs commenced. During this period, flocs and other sediments were deposited through the sand media due to the effects of particle transport and attachment mechanisms. The deposited micro and macro particles reduced the effective pore area of the sand media, thus forming a deep bed deposit, which improved the quality of the filtered water. 


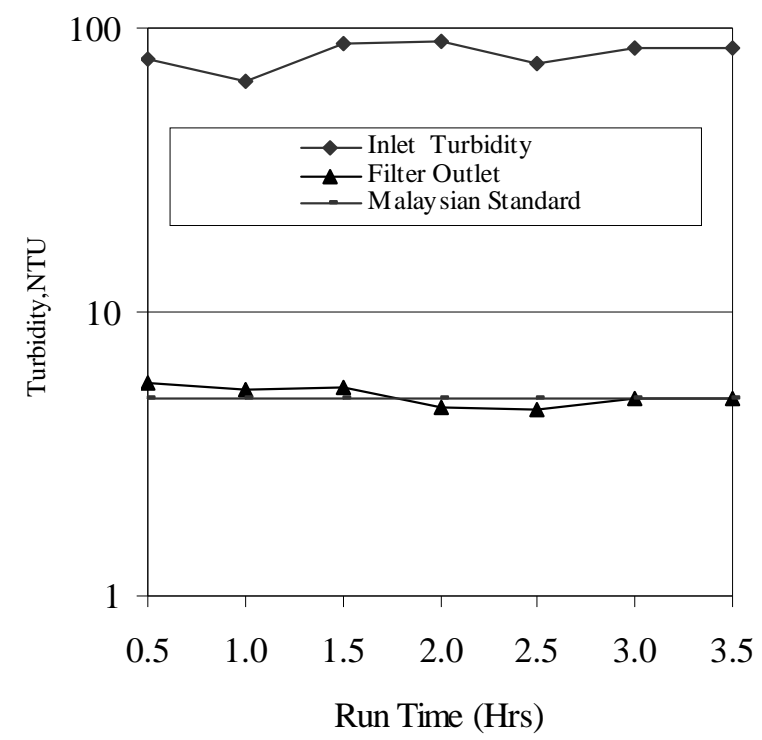

Fig. 3: Turbidity of inlet and filtered outlet at a dose of $30 \mathrm{mg} / \mathrm{L}$ using $25 \% \mathrm{w} / \mathrm{w}$ oil extracted M. oleifera seed (Initial Turbidity of water 65 to 90 NTU).

\subsubsection{High turbidity $(\geq 100 \mathrm{NTU})$}

Figure 4 represents the average results for high turbidity varying from 100 to 260 NTU. The effective dosage of $M$. oleifera used varied from $50 \mathrm{mg} / \mathrm{l}$ to $70 \mathrm{mg} / \mathrm{l}$. The turbidity removal after coagulation and settling was found to improve with an increase in initial turbidity of raw water and time of filter run. For example, for water with an initial turbidity of $100 \mathrm{NTU}$, the residual turbidity recorded was 7 NTU corresponding to a removal $93 \%$. After two hours the initial raw water turbidity increased to 134 NTU, while the residual turbidity reduced to 5.5 NTU corresponding to $96 \%$ removal. This observation may be explained in terms of the increase in suspended particles available with an increase in initial turbidity. This increase created more sites for adsorption and inter-particle bridge formation resulting in an increase in particle collision frequency and agglomeration rate leading to decrease in residual turbidity [4]. As much as $98 \%$ of the solids were removed and the turbidity of the filtered water was between 4.5 and 7 NTU.

\subsection{4. $\mathrm{pH}$ Variation}

Figure 4 indicates the relationship between the $\mathrm{pH}$ of raw water and treated water for average results from four experimental runs. The $\mathrm{pH}$ of raw water varied from 7.23 to 7.84 (average of 7.43 and standard deviation of 0.144 ). In general the $\mathrm{pH}$ of the treated water was slightly lower than the $\mathrm{pH}$ of the raw water.

In a laboratory based study in which alum and M. oleifera, shelled and non-shelled seed were used as coagulants, the $\mathrm{pH}$ value was found to be constant in the case of M. oleifera while it decreased from 7.6 to 4.2 with addition of alum [2]. This implied that further chemical addition was necessary in order to correct the $\mathrm{pH}$ of the treated water to values between 6.5 and 9 to meet the Malaysian Standard. The effect of M. oleifera on the $\mathrm{pH}$ of 
the water was insignificant and no $\mathrm{pH}$ adjustment for the water was required after treatment. This is a major advantage when M. oleifera is used for coagulation.

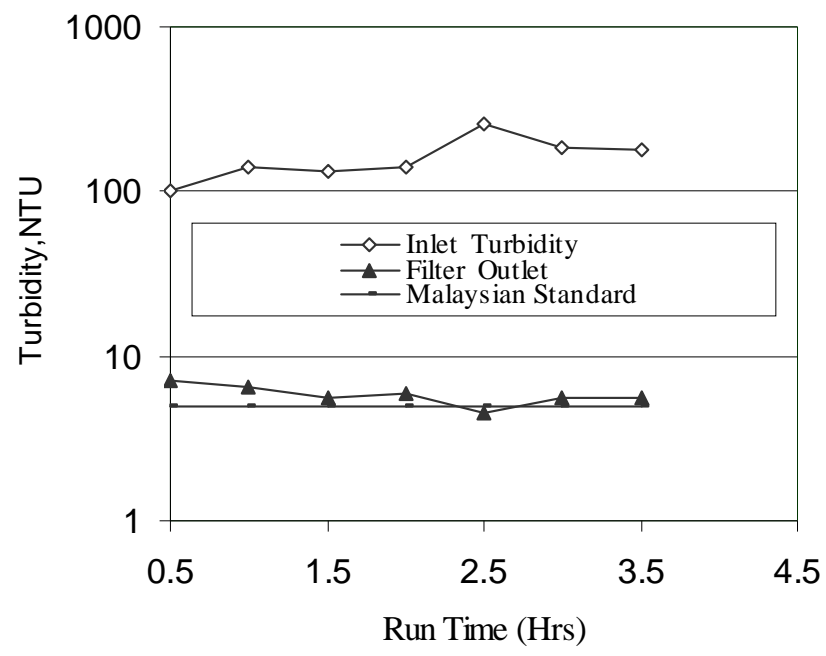

Fig. 4: Turbidity of inlet and filtered outlet at a dose of 50 to $70 \mathrm{mg} / 125 \% \mathrm{w} / \mathrm{w}$ oil extracted M. oleifera seed (Initial Turbidity of water 100 to 260 NTU).

\subsubsection{Alkalinity variation}

Figure 5 shows the composite results of variation of alkalinity of both raw and treated water as a function of time for three experimental runs. The alkalinity of the raw water ranged between 1.5 and $2.2 \mathrm{mg} / \mathrm{CaCO}_{3}$. It was observed that the alkalinity of the treated water was generally equal to that of the raw water. In very few instances the alkalinity of treated water was slightly less than that of the raw water with a maximum variation of 0.2 $\mathrm{mg} / \mathrm{l} \mathrm{CaCO}_{3}$.

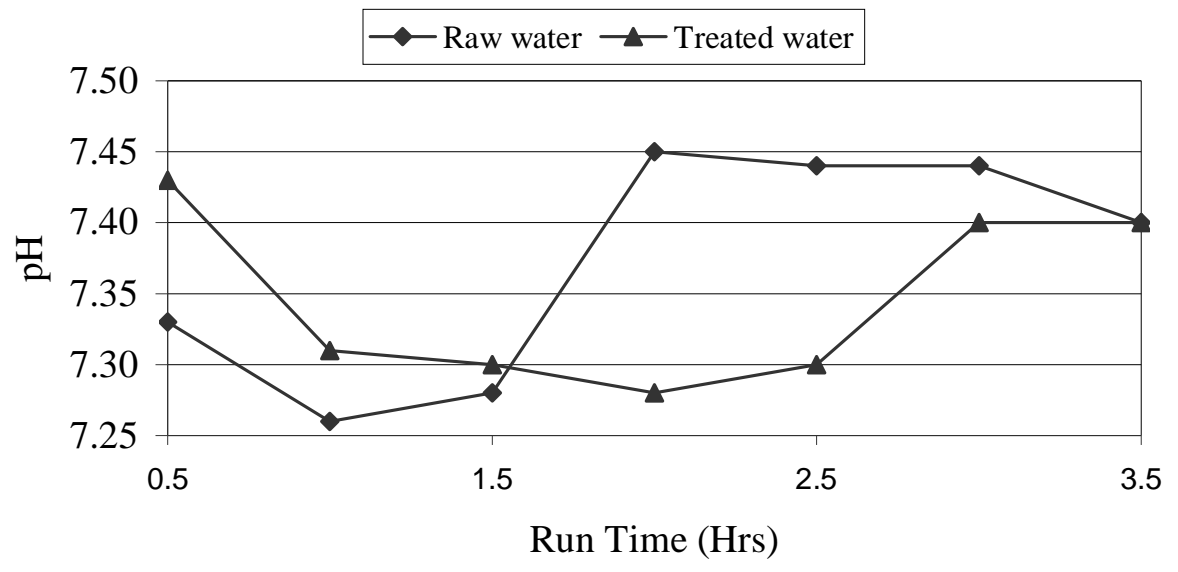

Fig. 5: pH of inlet and filtered outlet at a dosage of $30 \mathrm{mg} / 125 \% \mathrm{w} / \mathrm{w}$ oil extracted $M$. oleifera seed. 
The low alkalinity of the raw water as well as the treated water could initiate corrosion problems in the distribution networks. It is common practice in water treatment to add alkalinity in the form of bicarbonate or lime to increase the alkalinity. With M. oleifera, it may therefore be necessary to add lime or soda ash to alleviate the possible occurrence of such a problem.

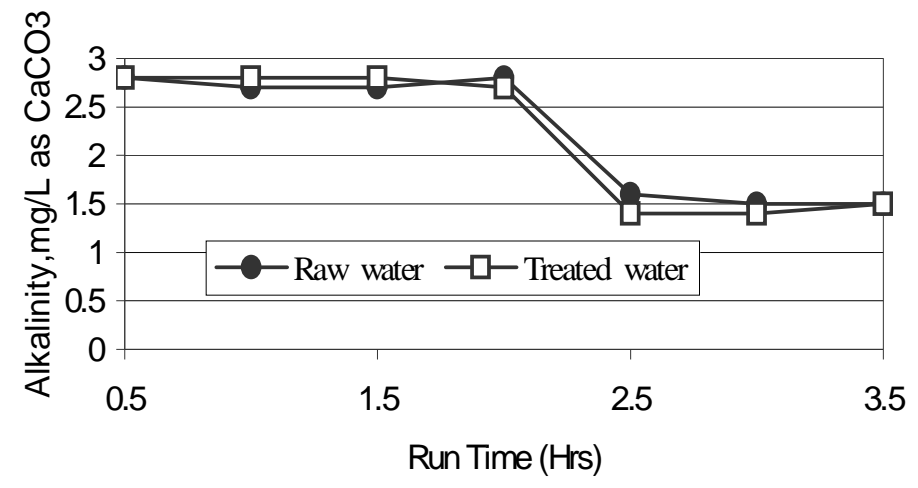

Fig. 6: Alkalinity of inlet and filtered outlet at a dose of $30 \mathrm{mg} / 125 \% \mathrm{w} / \mathrm{w}$ oil extracted M. oleifera seed.

\subsubsection{Head Loss Development}

Development of head loss at four different depths, 10, 20,30, and $40 \mathrm{~cm}$ from the sand surface are shown in Figure 7. The figure shows the average head loss development for five runs carried out after back washing. The raw water turbidity varied between moderate and high with an average of 162 NTU. The variation of head loss with time was recorded from the third run after back washing as the results of the second run after backwashing were not available because of malfunctioning of the manometers. It was observed that the head loss at $40 \mathrm{~cm}$ after 60 minutes was $6.3 \mathrm{~cm}$, which increased gradually with time up to $24 \mathrm{~cm}$ after 6 trials $(18 \mathrm{Hrs})$. It then dropped to $15.7 \mathrm{~cm}$. Breakthrough occurred after 19 hours of operation and the turbidity of the filtered water increased from 4.5 NTU to 9.7 NTU. The experimental runs were then terminated and the filter was backwashed.

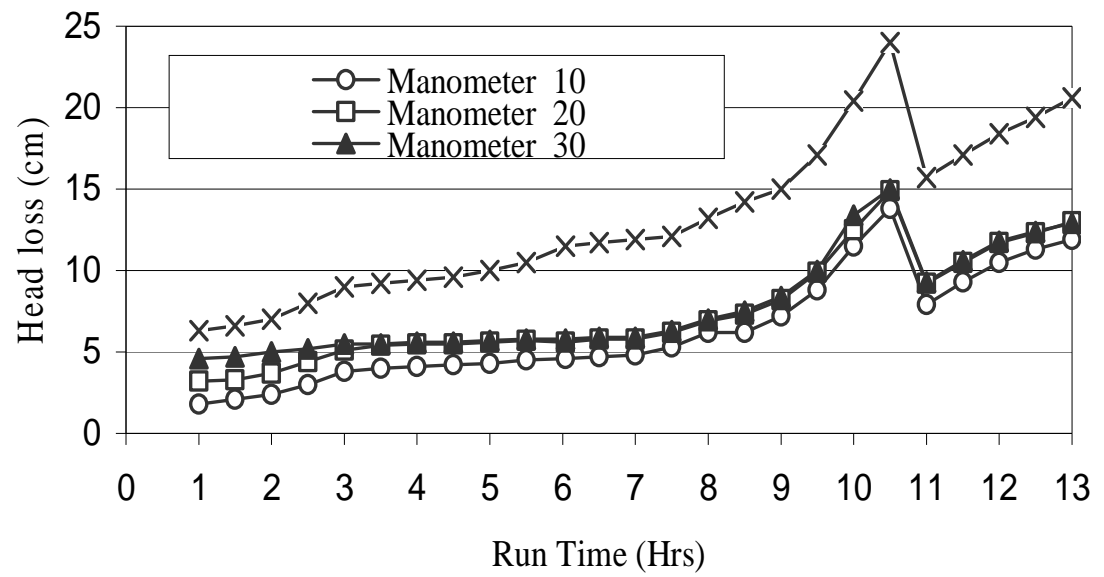

Fig.7: Variation of filter head loss at inlet and filtered outlet. 


\subsection{Filter Head Loss and Residual Turbidity}

The relationship between the filter head loss and residual turbidity is presented in Figure 8, which represents a composite of three experiments. The average initial turbidities of low, medium and high turbidity were 18.5, 82.8 and 142 NTU respectively. It was observed that the residual turbidity decreased with increase in the head loss. The highest turbidity removal was at residual turbidity of $4.5 \mathrm{NTU}$, which was obtained for raw water with high turbidity and medium turbidity. The corresponding head loss was 9.6 and $11.9 \mathrm{~cm}$ respectively.

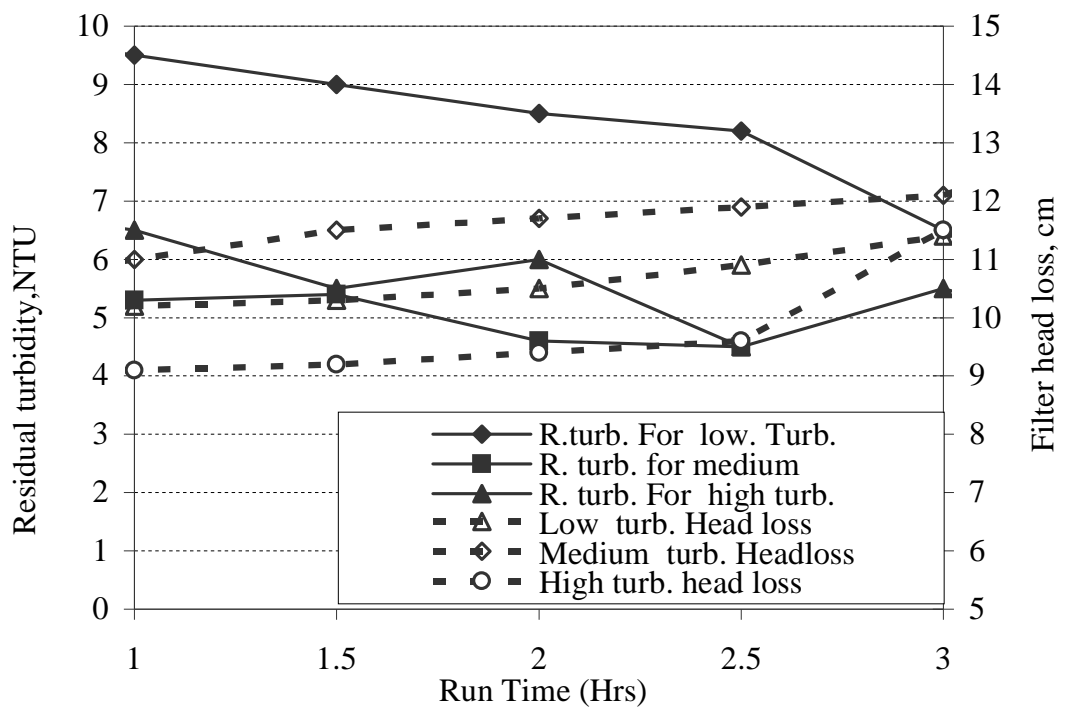

Fig. 8: Filter head loss and residual turbidity variation.

\subsection{Summary of findings}

1 Effective doses of 20 and $30 \mathrm{mg} / \mathrm{l}$ of $M$. oleifera for low $(<50 \mathrm{NTU})$ moderate turbidity $(<100 \mathrm{NTU})$ and $50-80 \mathrm{mg} / \mathrm{l}$ for high turbidity $(>100 \mathrm{NTU})$ feed water respectively removed an average $96 \%$ of the initial turbidity of the raw water.

2 The effective dose of $M$. oleifera used for the test runs was obtained from the jar test results. For low turbidity it was $20 \mathrm{mg} / \mathrm{l}$, moderate turbidity $30 \mathrm{mg} / \mathrm{l}$ and for the high turbidity the dosage varied from 50 to $80 \mathrm{mg} / \mathrm{l}$ depending on the initial turbidity.

3 Analysis of the water treated in the pilot plant showed that M. oleifera did not significantly affect the $\mathrm{pH}$ or alkalinity after treatment.

4 The maximum filter head loss, after which the breakthrough occurred, was $24 \mathrm{~cm}$ at the depth of $40 \mathrm{~cm}$. The corresponding operation time was 18 hours.

5 The residual turbidities measured during most of the test runs satisfied the Malaysian Guideline for Drinking Water Supplies. 


\section{ACKNOWLEDGEMENT}

The authors are grateful to the Malaysian Ministry of Science, Technology and Innovation for funding the research under the IRPA Grant no. 09-02-04-0089 program Cycle 2 and 3, 1998.

\section{REFERENCES}

[1] A. Ndabigengesere, K.S. Narasiah, and B.G. Talbot, "Active Agent and Mechanism of Coagulation of Turbid Waters Using Moringa oleifera", Water Research, Vol. 2, pp. 703-710, 1995.

[2] A. Ndabigengesere, K.S. Narasiah, "Quality of Water Treated by Coagulation Using Moringa oleifera seeds", Water Research, Vol. 32, No. 3, pp. 781-791, 1998.

[3] S.A. Muyibi, "Moringa oleifera Seed Extract in Water Treatment", Journal-Institution of Engineering, Malaysia, Vol. 59, No. 3, pp. 37 - 50, 1998.

[4] S.A. Muyibi. and L.M. Evison, "Optimizing Physical Parameters Affecting Coagulation of Turbid Water with Moringa oleifera seeds", Water Research, Vol. 29, No. 12, pp. 2689-2695, 1995.

[5] T, Okuda, A.U. Baes, W. Nishijima, M. Okada, "Coagulation mechanism of salt solution extracted active component in Moringa oleifera", Water Research, Vol. 35, No. 3, pp. 830834, 2001.

[6] S.A. Muyibi and C.A. Okuofu, "Coagulation of Low Turbidity Surface Waters with Moringa oleifera Seeds", International Journal of Environmental Studies, Vol. 48, pp. 263-273, 1995.

[7] S.A. Muyibi and C.A. Okuofu, "Softening Hard Waters with Moringa oleifera Seed Extracts", International Journal of Environmental Studies, Vol. 50, pp. 247-257, 1996.

[8] S.A. Muyibi. and L.M. Evison, "Coagulation of Turbid Water and Softening of Hard Water with Moringa oleifera Seeds", International Journal of Environmental Studies, Vol. 49, pp. 247-259, 1996.

[9] F. Kasser, C. Werner, and O. Nahayo, "Rural Water Treatment Using Moringa oleifera Seeds as Coagulant", Natural Resources Development, 33, 33-47, Institute for Scientific Cooperation, Tubingen, Germany, 1990.

[10] J.P. Sutherland, G.K. Folkard, and W.D. Grant, "Development of Robust Water Treatment Incorporating Natural Coagulants", Field Study Report, Environmental Engineering Group, Department of Engineering, University of Leicester, UK, 1992.

[11] G.L. McConnachie G.K. Folkard, M.A. Mtawali, and J.P. Sutherland, "Field trials of appropriate hydraulic flocculation process", Water Research, Vol. 33, No. 6, pp. 1425-1434., 1999.

[12] S.A. Muyibi, J.M.M.N. Megat., H.L. Lam, K.L. Tan, "Effects of oil extraction from Moringa oleifera seeds on coagulation of turbid water", International Journal of Environmental Studies, Vol. 59, No. 2, pp. 243-254, 2002.

[13] S.A. Muyibi, S.A. Abbas, J.M.M.N. Megat, A. Fakhrul-Razi "Enhanced coagulation efficiency of Moringa oleifera seeds through selective oil extraction". IIUM Journal of Engineering(in press 2003). 
[14] American Public Health Association (APHA), American Water Works Association (AWWA) and Water Environment Federation (WEF) Standard Methods for the Examination of Water and Waste-water, $20^{\text {th }}$ edition APHA Publication Office, Washington D.C., 1999.

\section{BIOGRAPHIES}

Dr. Suleyman Aremu Muyibi was born in 1950 in Osogbo, Osun State Nigeria. He earned his BS in Engineering from the University of Central Florida, USA in 1979, MEng from the University of Benin, Nigeria in 1987 and $\mathrm{PhD}$ in Environmental Engineering from the University of Newcastle upon Tyne, UK in 1995. He also earned a Diploma in Islamic Studies (DIS) from the International Islamic University Malaysia in 2001. He is a member of the Nigerian Society of Engineers (NSE), a Registered Civil Engineer (COREN, Nigeria), and a member of the Malaysian National Committee on Irrigation and Drainage (MANCID), and Group Leader of the Environmental Biotechnology Engineering Research Group (EBERG) at the International Islamic University Malaysia. $\mathrm{He}$ is currently an Associate Professor in the Department of Biotechnology Engineering, Faculty of Engineering, International Islamic University Malaysia. His area of research interest include environmental biotechnology, water supply and treatment, wastewater treatment, water pollution control, development of bioactive materials for use in water and waste treatment and environmental hydraulics. He has authored and co-authored more than 50 publications in journals, conferences, technical reports, and a textbook.

\section{Ahmed Hissein M Birima}

BS (Libya), MSc (UPM). Ahmad is currently a PhD candidate in Water Engineering at the Department of Civil Engineering, Faculty of Engineering, Universiti Putra Malaysia.

\section{Dr. Thamer Ahmad Mohammed}

BSc. (Mosul), MSc. (Baghdad), PhD (UPM). Dr. Thamer is currently an Associate Professor in the Department of Civil Engineering, Universiti Putra Malaysia. His research interest includes surface and groundwater modelling with environmental considerations and environmental hydraulics. Dr. Thamer has authored and co-authored more than 20 publications in journals, conferences and technical reports.

\section{Ir. Megat Johari M. M. Noor}

B.Sc. (Hons), M.Sc. (Loughborough), P.Eng. M.I.E.M., M.I.F.S., MIWA, MMANCID. Ir. Megat is an Associate Professor in the Department of Civil Engineering, Universiti Putra Malaysia. His areas of research interest include Design and Development of Membrane Bioreactor for Treating High Strength Municipal Wastewater, M. Oleifera Seeds Extracts as a Coagulant and Coagulant Aid in Water Treatment, the use of Natural Coagulants for Water Treatment, Tertiary Treatment of Industrial and Domestic Wastewater using Microfiltration, Soil Stabilization, and Sludge Treatment for Safe Disposal and Recoveries. Ir. Megat has authored and co-authored more than 50 publications in journals, conferences and technical reports. 